\title{
Smoking control policies in private health insurance in California: results of a statewide
} survey

\author{
Helen Halpin Schauffler, Daniel Gentry
}

\begin{abstract}
Objective-To estimate the extent to which private health insurance companies in California promote smoking control among their policy holders through premium differentials based on smoking status and through benefits that cover smoking cessation treatment.
\end{abstract}

Design - A mail questionnaire sent to a random sample of private insurance companies licensed by the California Department of Insurance to sell health insurance ( $54 \%$ response rate). For those respondents that sold health insurance in California in $1991(n=48)$, and had adopted a smoking control policy $(n=$ 26), a telephone interview was conducted to obtain additional detail on specific policy designs ( $81 \%$ response rate).

Participants - Private health insurance companies that sold health insurance policies in California in 1991. Respondents to both the mail questionnaire and the telephone interview were key informants from the underwriting departments of the insurance companies sampled.

Results - Approximately $27 \%$ of the private health insurance companies surveyed reported that they risk-rate health insurance premiums using smoking status, with average premium differentials of $16 \%$ for individual policies and $10 \%$ for small-group policies. Only one $(2 \%)$ of the health insurers surveyed used smoking differentials for large-group policies, and only in a small pilot programme. The primary reasons private health insurers use smoking status to risk-rate health insurance premiums is to market their products to non-smoking individuals and small groups, and to discourage smokers from purchasing their products. Only one $(2 \%)$ of the health insurance companies surveyed sells any policies that cover smoking cessation treatment.

Conclusions - In 1991 only about $25 \%$ of private health insurers in California were using premium differentials based on smoking status in individual or smallgroup policies. Fewer that $5 \%$ of private health insurers were selling policies that cover smoking cessation services, despite a state mandate to offer smoking cess- ation treatment benefits, and recent public policy pronouncements at the Federal level encouraging their coverage.

(Tobacco Control 1994; 3: 124-129)

In a recent report by the Tobacco Policy Research Study Group on Reimbursement and Insurance in the US, the authors identified a critical need for increased information and understanding of the behaviour of health insurers in designing and offering incentives and reimbursement for smoking control. ${ }^{1}$ This paper examines the extent to which private health insurers in the State of California are promoting smoking control among their policy holders through the use of premium differentials and benefit policies. The specific smoking control policies examined include risk-rating health insurance premiums based on smoking status in the form of non-smoker discounts or smoker surcharges, and paying for smoking cessation services and nicotine-replacement therapy as covered health insurance benefits.

\section{Background}

Prior to 1980 , none of the health insurance companies in the US were offering non-smoker discounts, despite widespread adoption of this practice in the life insurance industry. ${ }^{2,3}$ The 1979 Surgeon General's report on smoking first proposed the practice of risk-rating health insurance using smoking status as an economic incentive to induce smokers to quit. ${ }^{3,4}$ In 1980 the US Public Health Service included "differential insurance premiums for smokers and nonsmokers by major ... health insurers," as one of the 1990 health objectives for the nation. ${ }^{5}$ The National Association of Insurance Commissioners adopted a model regulation in 1984 , referred to as the "wellness" regulation, that encouraged the use of economic incentives in health insurance to promote the practice of healthy lifestyles, including smoking cessation..$^{3,6}$ By 1987, the health insurance industry reported, based on the most comprehensive survey to date on the practice of riskrating, that approximately $14 \%$ of commercial health carriers and $16 \%$ of Blue Cross/Blue Shield Plans were offering non-smoker discounts on individual health insurance policies. ${ }^{7}$

In contrast to the practice of risk-rating, relatively little is known regarding the extent
School of Public California, Berkeley, California 94720, USA D Gentry 
to which health insurers offer coverage for smoking cessation treatments, including smoking cessation services and nicotine-replacement therapy. ${ }^{3,8}$ Public policy promoting coverage for smoking cessation and nicotine addiction treatments has emerged only very recently. The Surgeon General first proposed third-party coverage for smoking cessation treatments in the 1988 report on nicotine addiction. ${ }^{9}$ The Secretary of Health and $\mathrm{Hu}-$ man Services, in transmitting the 1990 Surgeon General's report on the benefits of quitting smoking, encouraged public and private health insurers to provide payment for effective smoking cessation services, based on the overwhelming body of evidence on the health benefits from quitting smoking, combined with the demonstrated effectiveness of smoking cessation services. ${ }^{10}$

However, the Health Insurance Association of America (HIAA), in a 1986 member survey, reported that none of the insurance companies responding offered counselling services for smoking cessation as a covered benefit. ${ }^{11}$ In 1991, HIAA identified one private health insurance carrier in the US, King County Medical Blue Shield in Washington State, that routinely provides coverage for smoking cessation in its health insurance plans ( $P$ Wright, personal communication).

In California, the State Insurance Code was amended in 1989 (Section 10123.6) to require that on or after 1 January 1990 every insurer issuing group disability insurance that covers hospital, medical or surgical expenses must offer (but is not mandated to provide) coverage of smoking cessation treatment in facilities licensed to provide alcoholism or chemical dependency services, and may require separate deductibles, co-payments, and overall cost limitations for treatment of nicotine addiction. ${ }^{12}$

The California mandate does not apply to health maintenance organisations (HMOs) or self-funded employee benefit plans, although Section 10123.14 of the State Insurance Code permits self-funded plans to offer such benefits. ${ }^{12}$

This paper presents the results of the first statewide assessment of smoking control policies in private health insurance in the US. It estimates the prevalence of these policies among private health insurance companies doing business in the state of California in 1991, and the extent to which they are offered on individual policies, compared to small- and large-group policies. The paper also details differences in the design features and approaches to implementing these policies. The results of this survey are intended to provide insurers, policy holders, employers, and public policy makers with current information on industry practices related to smoking control.

\section{Methods}

Using a 1991 listing of 1025 companies licensed to sell health insurance in the state of California provided by the California Department of Insurance, a simple random sample of 280 insurance companies was selected, such that each company had an independent and equal chance of selection. Some of the insurance companies included in the sampling list are held by common holding companies; however, organisations were considered separate entities for the purposes of this research as long as separate licenses have been issued. It is important to note that the list of insurers provided by the Department of Insurance does not include HMOs which are regulated separately in the state of California by the Division of Health Care Services Plans in the Department of Corporations. In addition, a majority of the large employers in the state self-fund their health insurance plans, and these self-insured plans are exempt from all state regulation. As a result, the private health insurance companies regulated by the California Department of Insurance represent $20-30 \%$ of all health insurance policies written in California, or between 5 to 8 million covered lives.

During April 1991 a mail survey was sent to the underwriting managers of the 280 insurance companies in the sample. Four weeks following the initial mailing a second copy of the questionnaire was sent to non-respondents. The mail survey response rate was $54 \%$ $(150 / 280)$.

The survey asked first if the insurance company currently writes health insurance policies in the state of California. If yes, the survey asked if the company: $a$ ) currently offers, $b$ ) has ever offered, or $c$ ) has seriously considered but chosen not to offer policy holders health insurance plans with: 1) a premium rating structure that utilises smoking status for either non-smoker discounts or smoker surcharges; and 2) coverage for smoking cessation or nicotine addiction treatment benefits. The companies were assured of strict confidentiality and were informed that data would be reported in aggregate or anonymous form only.

A major limitation in conducting this research was that the California Department of Insurance could not provide a listing of health insurance companies doing business in the state, but only a listing of insurance companies with current licenses to sell health insurance. Only $32 \%(48 / 150)$ of the respondents to the survey sold health insurance in California in 1991.

To assess the representativeness and potential response bias in our sample, we randomly sampled $20 \%(26 / 130)$ of the nonrespondents to the mail survey and telephoned them to ask if they sold any health insurance policies in California in 1991 (100\% response rate). Only $19 \%(5 / 26)$ responded affirmatively. As suspected, the proportion of companies licensed to sell health insurance that actually did so in California in 1991 was higher among the mail survey respondents $\left(\pi_{1}=\right.$ $32 \%)$ than among the non-respondents $\left(\pi_{2}=\right.$ $19 \%$ ). A comparison of the two proportions found that they are statistically significantly different $\left(95 \% \mathrm{CI}\left(\pi_{1}-\pi_{2}\right)=0.03-0.23\right)$. Based on these findings we estimate that approxi- 
mately $26 \%(267 / 1025)$ of the licensed insurance companies in California sold health insurance in 1991. Thus, we estimate that our final sample of 48 represents approximately $18 \%(48 / 267)$ of all health insurance companies selling health insurance in California in 1991.

Follow-up telephone interviews were conducted with the companies that responded affirmatively to one or more of the questions regarding health insurance policies for smoking premium differentials and/or smoking cessation treatment benefits $(n=26)$ to obtain additional details regarding policy design. Telephone interviews were completed with 21 health insurers ( $81 \%$ response rate). At least five attempts were made to contact key informants, who included actuaries, underwriters, and compliance specialists. The telephone interviews collected more detailed information on the design and implementation of smoking control policies.

All proportions and standard errors presented in the paper refer to the full sample of 48 health insurance companies, unless otherwise noted.

\section{Survey results}

The proportion of private health insurance companies surveyed in California $(n=48)$ that has ever considered using smoking control policies (risk-rating premiums, and/or offering coverage for smoking cessation treatment benefits) is $54 \%$ (SE 7.2), and $40 \%$ (SE 7.1) of the insurance companies surveyed indicated that they have ever implemented one of these smoking control policies. The table presents prevalence figures by type of policy. The findings are discussed separately for risk-rating health insurance and coverage of smoking cessation benefits.

\section{RISK-RATING HEALTH INSURANCE}

A policy to risk-rate health insurance premiums using smoking status was considered by $47.9 \%$ (SE 7.2 ) of the private health insurers surveyed $(n=48)$, and is used by $27.2 \%$ (SE 6.4). Approximately half of the health insurers who use risk-rating based on smoking status indicated that they have adopted the policy since 1987 .

The health insurers that have considered a policy of risk-rating health insurance using smoking status, and have rejected the idea $(12.5 \%$, SE 4.8$)$, reported having no plans to implement a rate structure based upon smoking status in the future. Reasons given most frequently for not implementing smoking differentials for health insurance include concerns regarding administration of the policy, inadequate data systems to support implementation, uncertainty regarding the correct smoking differential to use in setting rates, and selling only group health insurance. An additional $8.3 \%$ (SE 4.0 ) of the health insurers surveyed reported that they had discontinued using smoking status to risk-rate health insurance because of the administrative burden and questions regarding the cost-effectiveness of verifying self-reported smoking status, lack of interest and participation in the policy (particularly among Medicare Supplement policy holders), and corporate decisions to no longer sell health insurance.

All of the private health insurers that riskrate health insurance premiums based on smoking status stated that one of the major reasons for adopting this practice was as a marketing strategy to attract non-smokers. The other major reasons cited include reducing health care costs, attempting to make insurance costs more equitable, and reducing risk levels.

Among all of the health insurers surveyed, $19 \%$ (SE 5.6) market smoking differentials as a "non-smoker discount," while $8 \%$ (SE 3.9) market the differentials as a "smoker surcharge." The differentials range in value from $10 \%$ of premium to $35 \%$, with a mean of $15.8 \%$. Approximately half of the health insurers who are using risk-rating conduct claims analysis by smoking status and set their smoking differentials based on their own claims experience. The other companies rely on advice from their actuaries and industry standards to select a smoking differential.

The proportion of direct premium income that is subject to non-smoking discounts ranges from $67 \%$ to $85 \%$, in contrast with the proportion of direct premium income subject to smoking surcharges, which is only $5 \%$ to $10 \%$. One company that had marketed nonsmoker discounts for six years recently changed its policy to a smoker surcharge. This company indicated that the pendulum had swung away from marketing to the non-smoker to an overt attempt to discourage smokers. Smoking surcharges were adopted as part of an overall marketing strategy to decrease the number of policy holders who are high utilisers or at risk of high utilisation.

The proportion of all health insurance companies surveyed that offer the smoking differential on individual health insurance policies, including major medical and hospital indemnity insurance, is estimated to be $23 \%$ (SE 6.2), while only $10 \%$ (SE 4.3) offer

Table Prevalence of smoking control policy adoption among private health insurers in California in $1991, n=48$

\begin{tabular}{lcc}
\hline Policy status & $\begin{array}{c}\text { Risk-rate premiums } \\
\text { using smoking status } \\
\%(S E)\end{array}$ & $\begin{array}{c}\text { Offer smoking cessation } \\
\text { treatment benefits } \\
\%(S E)\end{array}$ \\
\hline Policy ever considered & $47.9(7.2)$ & $12.5(4.8)$ \\
Policy idea rejected & $12.5(4.8)$ & $8.3(4.0)$ \\
Policy ever adopted & $35.4(6.9)$ & $4.2(2.9)$ \\
Policy in current use & $27.2(6.4)$ & $2.1(2.1)$ \\
\hline
\end{tabular}


smoking differentials on small group health insurance policies. All of the smoking differentials for small-group policies have been adopted since 1987. The smoking differentials on small-group health insurance are lower than those applied to individual policies, ranging from $8 \%$ to $13 \%$ of premium, with a mean of $9.8 \%$. Only one company reported using risk-rating based on smoking status for large-group health insurance. This company implemented a pilot programme in 1989, offering an $8 \%$ discount to non-smokers in both small and large groups. At present the risk-rating applies to only $5 \%$ of the company's total premium income, as it is still being conducted on a test marketing basis only.

All of the health insurance companies that offer smoking differentials require potential policy holders to self-report their smoking status. A non-smoker is defined as someone who has not smoked (or used tobacco products) in the last 12 months. Only one company strayed from this definition, requiring policy holders not to have smoked in the past three years to qualify as non-smokers. Approximately $10 \%$ (SE 4.3) of all of the health insurers surveyed require, prior to issuing a policy, a physical examination that includes a urinalysis test for cotinine to verify selfreported smoking status.

COVERAGE FOR SMOKING CESSATION TREATMENT BENEFITS

Among the 48 private health insurance companies surveyed in California, only $4.2 \%$ (SE 2.9) reported ever offering smoking cessation benefits as either treatment for tobacco-related disease or as part of a larger prevention benefit package. One insurance company that had offered a smoking cessation benefit in the past reported that they only had a few remaining group health insurance policies in California, none of which include smoking cessation benefits. The one health insurer still offering a smoking cessation benefit for nicotine gum in its group health insurance plans indicated that it was required to do so under the 1989 amendments to California's insurance code. ${ }^{12}$ However, none of its employer groups had ever exercised their option to include a smoking cessation benefit in a large group health plan. Only one other insurance company surveyed indicated any knowledge of the California insurance code requirements, and had not developed smoking cessation benefits because they sell only Preferred Provider Organization (PPO) plans to large groups that have expressed no interest in these benefits.

An additional $8.3 \%$ (SE 4.0 ) of the private health insurance companies surveyed have seriously considered including a smoking cessation treatment benefit in their health insurance policies, but none of these companies have plans to implement such a policy in the future. Reasons given for failure to adopt smoking cessation treatment benefits include lack of information on how to structure and price these benefits, questions of cost-effectiveness, and lack of demand for specific products.
In addition, one company indicated that the expected utilisation of a smoking cessation treatment benefit by policy holders would be too low to merit its development, given that only $25 \%$ of their policy holders smoke, and only $15 \%$ of smokers would be expected to participate in a smoking cessation programme, ultimately serving only 3 to $4 \%$ of their policy holders.

\section{Discussion}

Our findings suggest that in 1991 nearly half of the private health insurers in California had seriously considered risk-rating premiums based on smoking status and that slightly more than one quarter were using smoking differentials in individual or small-group policies. Use of smoking differentials for large-group health insurance, however, remains rare with only one example from our survey of a pilot test for large-group health insurance.

We have estimated that our sample represents approximately $18 \%$ of all of the private health insurers that sold health insurance policies in California in 1991. However, we do not know how generalisable the results are to the current health insurance market in California, given the tremendous chaos in the health insurance industry and the rapid entry and exit of firms. The results are not generalisable to HMOs, self-funded employer plans, Medicaid or Medicare. In addition, we are not certain how generalisable the findings are to private health insurers operating outside California, although many of the companies included in our survey are national corporations, not restricted to the California market.

Some additional information is available regarding the practices of these other sectors of the health insurance industry in California and nationally. A 1991 survey of large employers (more than 500 employees) in California found that only $2 \%$ had implemented a risk-rating policy in any of the health insurance plans they offered their employees (including HMOs, self-funded plans, and private health insurance plans), and that $15 \%$ offered health insurance plans that covered smoking cessation services, primarily through HMOs. ${ }^{13}$ Less than $2 \%$ of these large employers offered coverage for smoking cessation treatment in their selffunded plans or in the PPO or private health insurance plans they offered to their employees. $^{13}$

Medicaid does not charge its recipients any premiums, so that risk-rating does not apply to the Medicaid population in any state. However, since 1984 the California Comprehensive Perinatal Services Program has reimbursed participating providers for smoking cessation counselling services provided to eligible women (pregnant women with incomes less than $200 \%$ of poverty level), although these providers are not mandated to provide smoking cessation counselling under the programme. ${ }^{14}$ The federal Medicare programme that covers the elderly and disabled neither risk-rates health insurance premiums nor covers smoking cessation treatment benefits. ${ }^{15}$ No comparable 
data are available on the prevalence of smoking control policies among HMOs in California or nationally. In 1987, the estimated proportion of private health insurance companies practising risk-rating using smoking status from a national survey was $14 \%$ with an average industry smoking differential reported of $10 \%$ of premium.?

California PERS (Public Employee Retirement System), a health insurance purchasing alliance that covers more than 926000 public and non-public employees and retirees in the state, does not charge smoking premium differentials in any of the 24 plans it offers, and only began to require coverage of smoking cessation drugs in $\mathrm{HMO}$ plans effective 1 August 1993. Approximately $76 \%$ of PERS members are in HMOs. The HMO standard benefit design under California PERS currently requires coverage for "one cycle or course of treatment of smoking cessation drugs, including chewing gum and patches per calendar year. The copayment must be $\$ 5.00$ for a 30 day supply. The health plan must also require the member to attend smoking cessation classes or programs in conjunction with the use of smoking cessation drugs. Plans can require members to pay a portion or all of the cost of the smoking cessation classes or programs. Plans can require members to pay the cost of the smoking cessation drugs initially and reimburse the member minus the copayment(s) upon the successful completion of a smoking cessation program.",16

Without exception, the primary reason private health insurers in California gave for adopting smoking differentials is to market their products to non-smokers, and to discourage adverse selection by smokers. The increasingly competitive private health insurance market in California, and the desire to attract healthy, low-risk policy holders, are the driving forces in considering and adopting smoking premium differentials. However, concerns regarding the burden of administering these policies, as well as questions regarding the actuarial value of the differential and the cost-effectiveness of risk-rating, remain major barriers to adoption of smoking differentials, particularly for large groups.

With the creation of large purchasing alliances, like California PERS, that cover persons who have previously been covered by individual and small-group policies, it is expected that the practice of risk-rating may decline over time. Large employers have concluded that risk-rating is probably not costeffective, as there is no evidence that it has any effect on reducing smoking rates and the administrative costs associated with implementing individual risk-rating are very high. ${ }^{13}$ The major effect of risk-rating is to make health insurance less affordable for the population that can least afford it and may need it most. ${ }^{17}$ Thus, we conclude that the practice of risk-rating is not consistent with the major goal of the Clinton health care reform plan universal access to private health insurance regardless of risk status. ${ }^{18}$ The Clinton Health Security Act as it was introduced in October
1993 prohibits individual risk-rating of health insurance premiums. ${ }^{18}$

Despite state legislation that requires all licensed health insurers to offer coverage of treatment for nicotine addiction in group policies, fewer than $5 \%$ of the health insurers surveyed in California in 1991 reported any knowledge of this mandate, and only $2 \%$ had developed benefits for treatment of nicotine addiction. None of the health insurers surveyed reported having any current policies that covered smoking cessation services or treatments for nicotine addiction. Neither recent public policy pronouncements at the Federal level encouraging private health insurers to cover smoking cessation services ${ }^{4,5}$, nor the state mandate ${ }^{12}$, appear to have had any influence on the behaviour of private health insurers in California in 1991 with respect to offering coverage for smoking cessation treatment.

In many respects, low compliance with the state mandate is not surprising, because the state only regulates licenses to sell health insurance. Monitoring compliance would be difficult given that the state does not know which companies that have been issued licenses currently write health insurance policies. The situation is no different at the national level. Neither the Health Insurance Association of America nor the National Association of Insurance Commissioners can provide an accurate estimate of the number of health insurers in the US. Also, the California mandate as enacted is relatively weak, requiring only that insurers offer, but not provide, benefits for treatment of nicotine addiction. Mandates that require health insurers only to offer benefits are largely symbolic, serving a political purpose to appease the interests of the service providers that support coverage of these additional benefits. A mandate only to offer benefits represents a compromise that balances these interest group demands against those who argue that benefit mandates increase total health care costs and decrease access to basic health insurance. ${ }^{19,20}$

The potential impact of the state mandate on smoking cessation treatments is relatively small even if compliance were 100 percent, since over $70 \%$ of Californians are estimated to receive their health insurance coverage from HMOs, self-funded employer plans, or public insurance programmes that are not subject to the regulation. ${ }^{19}$ Lack of awareness of the California mandate and lack of demand for coverage of smoking cessation services have resulted in very little development and no current sales of health insurance policies with coverage for smoking cessation services or treatment of nicotine addiction.

However, health care reform in the US presents an important opportunity to increase coverage of smoking cessation services through the definition of comprehensive preventive services within a federally mandated uniform benefit package. Requiring coverage for smoking cessation services for all Americans would be entirely consistent with previous federally policy calling for increased coverage for smok- 
ing cessation services by all public and private health insurers, as well as the Clinton health care reform plan which seeks to increase access to preventive care. ${ }^{9,10,18}$ However, the President's Health Security Act, as it was introduced in October 1993, only provides for the provision of health education and training classes for smoking cessation at the discretion of the health plan, and covers physician advice and counselling as part of the periodic health examination. ${ }^{18}$

This research was supported by a grant from the University of California Tobacco-Related Disease Research Program to the University of California, Berkeley, "Tobacco and Related Disease: Law, Policy and Politics," 7/1/90-6/30/92.

The authors gratefully acknowledge Jaclyn Hausman and Marina Pascali for their research assistance in data collection.

1 Parkinson MD, Schauffler HH, Kottke TE, et al. Report of the Tobacco Policy Research Study Group on Reimbursement and Insurance in the United States. Tobacco Control 1992; 1(suppl):S52-S56.

2 Brailey AG. The promotion of health through insurance. $N$ Engl f Med 1980; 302(2): 51-2.

3 US Department of Health and Human Services. Reducing the health consequences of smoking: 25 years of progress. $A$ report of the Surgeon General, 1989. Atlanta, Georgia: Centers for Disease Control, Office on Smoking and Health, 1989. (DHHS Publication No (CDC) 89-8411.) 4 US Department of Health, Education and Welfare. Smoking Department of Health, Education, and Welfare, Public Health Service, Office on Smoking and Health, 1979. DHEW Publication No (PHS) 79-50066.)

5 US Department of Health and Human Services. Promoting health/preventing disease: objectives for the nation. US Department of Health and Human Services, Public Health Service, 1980

6 National Association of Insurance Commissioners. Resolution on financial incentives. December 1984. NAIC Proceedings 1985; 1 :638.
7 National Association of Insurance Commissioners. Smokernonsmoker experience survey report. NAIC Proceeding 1987; 2:648-722.

8 Schauffler $\mathrm{HH}$, Parkinson $M$. Health insurance coverage for smoking cessation services. Health Educ $Q$ 1993; 20(2):185-206.

9 US Department of Health and Human Services. The health consequences of smoking : nicotine addiction. A report of the Surgeon General, 1988. Washington, DC: US Department of Health and Human Services, Public Health Service, Centers for Disease Control, 1988. (DHHS Publication No (CDC) 88-8406.

10 US Department of Health and Human Services. The health benefits of smoking cessation. US Department of Health and Human Services, Public Health Service, Centers for Disease Control, 1990. (DHHS Publication No (CDC) 90-8416.)

11 Health Insurance Association of America Evaluation report: employee, policy holder and community health report: employee, policy holder and community health promotion programs of HIAA member companies. Health Insurance Associrvices, 1986.

12 California Insurance Code, Section 10123.6 p 173, and Section 10123.14 , p 176. Amended by Stats 1989, c.688 ऽ 2.1989

13 Schauffler $\mathrm{HH}$. Integrating smoking control policies into employee benefits: a survey of large corporations in California. Am f Public Health 1993; 83(9):1226-30.

14 Comprehensive Perinatal Services Program, Title 22, California Code of Regulations, AB3012, 1984. California Department of Health Services, Maternal and Child Health Branch, Perinatal Care Section, Sacramento, CA

15 Schauffer $\mathrm{HH}$. Disease prevention policy under Medicare a historical and political analysis. Am f Prev Med 1993; 9(2):71-7.

16 California PERS. Health Plan Administration Division HMO Standard Benefit Definitions, Attachment 7, Prescription Drugs. 1 August 1993.

17 Schauffler $\mathrm{HH}$. Health insurance policy and the politics of tobacco. In: RL Rabin, SD Sugarman, eds, Smoking policy: law, politics and culture. New York: Oxford University Press, 1993, pp 184-207.

18 Health Security Act. President's Task Force on Health Care Reform. Washington, DC: White House, October 1993.

19 Glanz LH. Insurance benefits in the private sector: a decision for state legislators. Am $\mathcal{F}$ Public Health 1985; 75(11):1344-6.

20 Gabel JR, Jensen GA. The price of state mandated benefits. Inquiry 1989; 26:419-31. 